\title{
Review
}

\section{Selecting Graph Metrics with Ecological Significance for Deepening Landscape Characterization: Review and Applications}

\author{
Felipe de la Barra ${ }^{1,2}$, Audrey Alignier ${ }^{3,4} \mathbb{D}$, Sonia Reyes-Paecke ${ }^{1,5}$, Andrea Duane ${ }^{6}(\mathbb{D}$ \\ and Marcelo D. Miranda 1,2,*iD
}

\section{check for}

updates

Citation: de la Barra, F.; Alignier, A.; Reyes-Paecke, S.; Duane, A.; Miranda, M.D. Selecting Graph Metrics with Ecological Significance for Deepening Landscape Characterization: Review and Applications. Land 2022, 11, 338. https://doi.org/10.3390/ land11030338

Academic Editors: Carlos T.

López De Pablo and

Andreu Bonet-Jornet

Received: 28 January 2022

Accepted: 15 February 2022

Published: 25 February 2022

Publisher's Note: MDPI stays neutral with regard to jurisdictional claims in published maps and institutional affiliations.

Copyright: (C) 2022 by the authors. Licensee MDPI, Basel, Switzerland. This article is an open access article distributed under the terms and conditions of the Creative Commons Attribution (CC BY) license (https:// creativecommons.org/licenses/by/ $4.0 /)$
1 Faculty of Agronomy and Forest Engineering, Pontificia Universidad Católica de Chile, Santiago 7830436, Chile; fadelabarra@uc.cl (F.d.1.B.); sonia.reyes@uc.cl (S.R.-P.)

2 Center of Applied Ecology and Sustainability (CAPES), Pontificia Universidad Católica de Chile, Santiago 7830436, Chile

3 Unité Mixte de Recherche 0980 Biodiversité, Agroécologie et Aménagement du Paysage INRAE-ESA-Institut Agro, CEDEX, 35042 Rennes, France; audrey.alignier@inrae.fr

4 LTSER “Zone Atelier Armorique", CEDEX, 35042 Rennes, France

5 Center for Sustainable Urban Development, Pontificia Universidad Católica de Chile, Santiago 7830436, Chile

6 Forest Science Centre of Catalonia (CTFC), 25280 Solsona-Lleida, Spain; andrea.duane@ctfc.cat

* Correspondence: mmirands@uc.cl

\begin{abstract}
The usual approaches to describing and understanding ecological processes in a landscape use patch-mosaic models based on traditional landscape metrics. However, they do not consider that many of these processes cannot be observed without considering the multiple interactions between different land-use patches in the landscape. The objective of this research was to provide a synthetic overview of graph metrics that characterize landscapes based on patch-mosaic models and to analyze the ecological meaning of the metrics to propose a relevant selection explaining biodiversity patterns and ecological processes. First, we conducted a literature review of graph metrics applied in ecology. Second, a case study was used to explore the behavior of a group of selected graph metrics in actual differentiated landscapes located in a long-term socioecological research site in Brittany, France. Thirteen landscape-scale metrics and 10 local-scale metrics with ecological significance were analyzed. Metrics were grouped for landscape-scale and local-scale analysis. Many of the metrics were able to identify differences between the landscapes studied. Lastly, we discuss how graph metrics offer a new perspective for landscape analysis, describe the main characteristics related to their calculation and the type of information provided, and discuss their potential applications in different ecological contexts.
\end{abstract}

Keywords: landscape graph metrics; landscape heterogeneity; spatial graph; landscape characterization

\section{Introduction}

Landscape ecology appraises the interactions between spatial patterns and ecological processes, analyzing causes and consequences of spatial heterogeneity in ecosystems across a range of scales [1]. To understand the role of landscape heterogeneity in biodiversity, the habitat-matrix framework based on the theory of island biogeography [2] and the patch-mosaic model have been developed [3-7]. The first regards natural or seminatural habitat patches containing all resources necessary for organisms as being embedded in a homogeneous and hostile matrix usually composed of agricultural land cover [8]. The second considers the interactions between habitat patches as being dependent on mosaic properties such as resistance to the movement/dispersal of organisms [9]. One of the most important ideas to emerge from these approaches is that relationships at a local scale can produce effects at large spatial scales and vice versa, affecting the dynamics of the whole ecosystem [10-15]. Nevertheless, classical metrics do not directly account for these 
dynamics. More recently, Fahrig et al. suggested describing landscape heterogeneity on the basis of the composition (amount and diversity) and configuration (spatial arrangement) of landscape features [4].

To elucidate the impact of landscape heterogeneity on ecological process, many patchbased metrics have been developed to measure and synthesize the attributes and geometric characteristics (form, spatial relationship, and connectivity) of different patches associated with both single landscape elements and whole landscapes. Despite being extensively applied to relate landscape heterogeneity to ecological patterns, these metrics show limited integration of mosaic properties/functions (e.g., resistance to movement of organisms) $[7,16]$.

Landscape ecologists have turned to graph theory driven by a desire for a more functional approach to landscape quantification. In this framework, the landscape is represented by a set of nodes (habitat patches) connected by links or edges formed by potential ecological fluxes (e.g., dispersal or movement); together, these nodes result in a landscape graph [7,17]. Graph theory provides a formal foundation for studying the effects of landscape graph structure on ecological patterns. It also represents a powerful and effective way to analyze landscape connectivity [5,18-20]. Nevertheless, empirical ecological studies applying this framework are still scarce.

Graph theory has mostly been used in areas such as chemistry, physics [21,22], social sciences [23,24], and computer science [25]. Since its introduction to landscape ecology by Urban and Keitt in 2001 [26], it has been increasingly used to measure multiple aspects of connectivity in the context of conservation biology, land-use planning, and biogeography $[12,20,27]$. Consequently, a wide variety of metrics have been developed to characterize landscape graphs. These metrics involve either local descriptions related to structures, movements, and fluxes at the level of nodes and edges or global descriptions at the level of the entire graph (for reviews, see $[20,28]$. Consequently, the selection of appropriate measures that can explain the phenomenon being studied poses a challenge to landscape ecologists [20].

Most landscape ecological studies using graph theory treat landscapes from a habitatmatrix perspective $[10,20,26]$, are dedicated to one species or groups of species, and use dispersal strategies as the link between nodes [6,29,30]. However, because some species or groups of species are associated with (1) particular land-cover types (i.e., specialist species), (2) use different land-cover types to complete their life cycles (complementation/supplementation processes), and (3) can move between habitat patches (e.g., through neighboring or mass effects; [31,32], it is necessary to jettison the habitat-matrix perspective and consider the whole landscape mosaic. In addition, among the growing number of studies analyzing landscape connectivity with graphs of biodiversity [33], most are dedicated to animals (e.g., [5,6] whose nodes are habitat patches and whose links are migration or movement routes [10]. Studies investigating the effects of landscape connectivity on plants are scarce (see [34] for a review). Depending on their dispersal strategies, plants can spread and make connections between habitat patches, creating a landscape network [11].

The aim of this study is to provide a synthetic overview of existing metrics that characterize landscape graphs obtained from patch-mosaic models. We analyze their ecological meaning to propose a selection of metrics relevant to the landscape ecologist interested in explaining biodiversity patterns and ecological processes. Lastly, we illustrate their application in three contrasting agricultural landscapes in the LTSER Zone Atelier Armorique, Brittany, northwestern France.

\section{Materials and Methods}

\subsection{Landscape Graph Definition}

When applied to landscape ecology, graphs conceptualize an entity (i.e., landscape G) as a set of points or "nodes" given as follows [35]:

$$
V(G)=\left\{v_{1}, v_{2}, v_{3}, \ldots, v_{n}\right\}
$$


The edges $(E)$ or "links" represent neighborhood relations between the nodes $[7,36]$ and are represented as

$$
E(G)=\left\{u_{a} v_{a}, u_{b} v_{b}, \ldots, u_{n} v_{n}\right\},
$$

where each pair $e=(u, v)$ denotes a connection between two nodes in $V(G)[35,37]$. The two vertices $u$ and $v$ are adjacent in $G$, and the edge $e$ is incident to the vertices $u$ and $v$ [37]. The node $u$ is also called a neighbor of $v$ in $G$ and vice versa [37]. We used $N_{V}$ and $N_{E}$ to denote the number of nodes and the number of edges of a graph. We used the concepts of nodes and vertices indistinctly, in the same way as the concepts of edges and links.

\subsection{Bibliographic Review and Graph Selection}

We conducted a search for landscape graph metrics used in the field of ecology. In the Web of Science and Google Scholar sites, we searched combinations of the following keywords: "graph", "graph theory", "landscape", "spatial temporal analysis", and "landscape dynamic". We completed the search using the terms for the identified graph metrics as keywords (e.g., "closeness", "graph density", etc.). We only selected metrics that could be indicators of ecological processes or functions (i.e., with ecological significance).

We propose a new classification of such metrics according to different axes. For the scale of application, we differentiated between metrics defining the whole landscape structure (hereafter, landscape scale) and those analyzing the patch scale (hereafter, local scale). At the landscape scale, we classified metrics depending on whether they were informative about the heterogeneity, connectivity, clustering, or assortativity of the landscape. At the local scale, metrics were classified depending on whether they were informative about node importance, compositional heterogeneity, or configurational heterogeneity.

For each metric, we provide a comprehensive description, calculation, and interpretation of its values. We also propose hypotheses about the ecological significance of the metric and how it is related to primary productivity and biodiversity, and we list publications using or describing it.

\subsection{Graph Metrics Application in an Agricultural Forest Mosaic}

To explore the behavior of the different metrics in actual differentiated landscapes, we employed the abovementioned graph metrics to analyze landscapes in the Zone Atelier Armorique, a long-term socioecological research (LTSER) site, which is located in the northern part of Ille-et-Vilaine, Brittany, France $\left(48^{\circ} 36^{\prime} \mathrm{N}, 1^{\circ} 32^{\prime} \mathrm{W}\right)$ (Figure 1). The study area is a hedgerow network (also called bocage) landscape characterized by mixed dairy farming and cereal production. We selected three contrasting landscapes (A, B, and C in Figure 1; 900 ha each), 5-10 km apart and distributed along a gradient of hedgerow network density and farming practice intensity from the south to the north $[38,39]$. Graph analyses were performed with existing land-use maps of the three landscapes, considering eight land-use types: woodland, hedgerows, grassland, spring crops (mainly maize and pea), winter cereals (mainly winter wheat, barley, triticale, and oat), other crops (mainly apple orchards), water, and urban areas (roads and villages, including gardens).

We used the CONEFOR extension in ArcGIS $10.5[40,41]$ to produce a list of all the edges between patches less than $15 \mathrm{~m}$ apart. We arbitrarily decided on $15 \mathrm{~m}$ because of the large range of possible values for edge effects and plant dispersal capacity reported in the literature $[34,42,43]$. We then created landscape graphs on the basis of the edge list, using the igraph package in $R$ software and Qgis [44-46]. We explore and discuss the different metrics according to the local context and framed within the ecological context. Lastly, we illustrate the applications of relevant metrics (i) at the landscape scale, using landscapes A, B, and C, and (ii) at the local scale, using three representative nodes of landscape B (Figure 1a). 

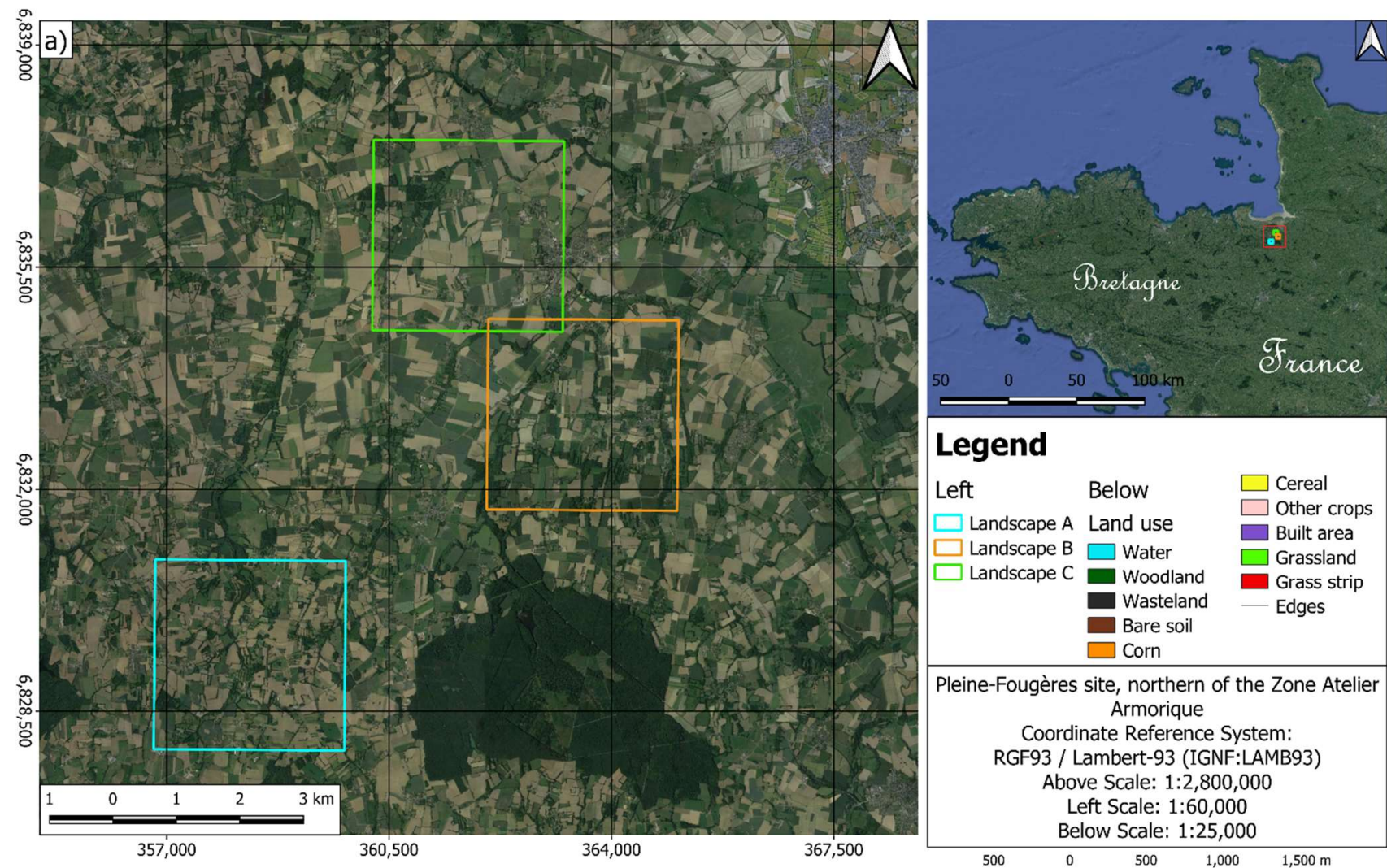

Pleine-Fougères site, northern of the Zone Atelier Armorique

Coordinate Reference System: RGF93 / Lambert-93 (IGNF:LAMB93) Above Scale: 1:2,800,000 Left Scale: 1:60,000 Below Scale: 1:25,000

$\begin{array}{lllll}500 & 0 & 500 & 1,000 & 1,500\end{array}$

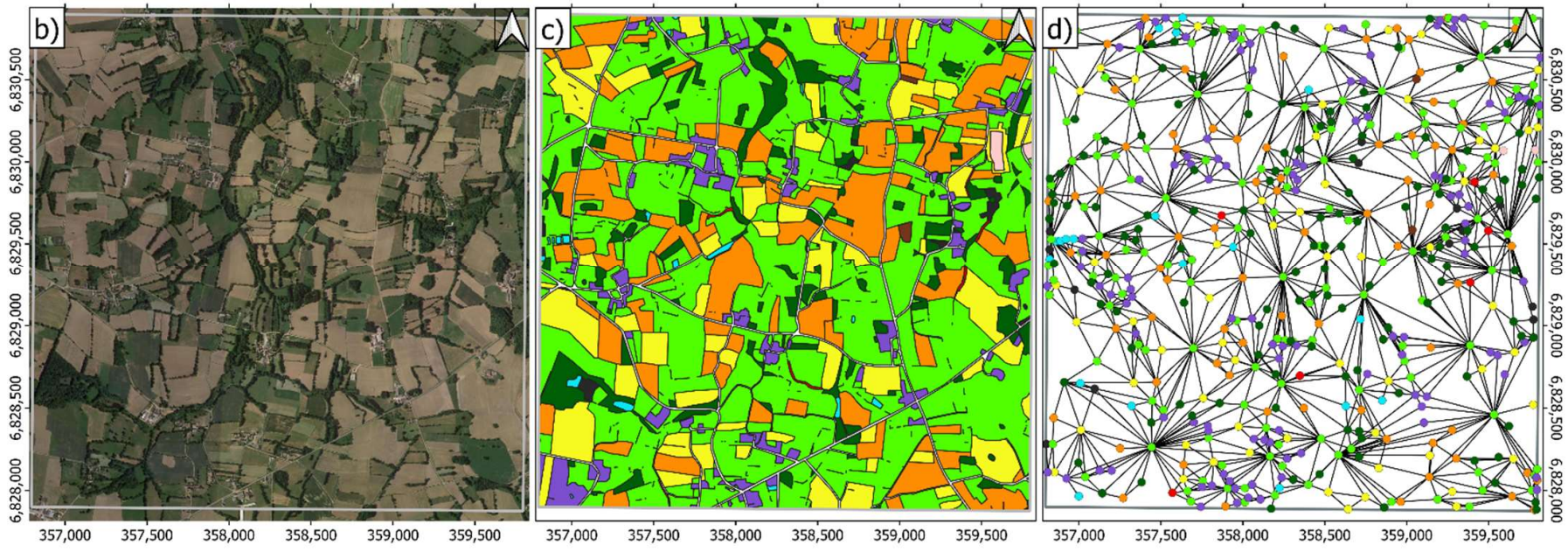

Figure 1. The Zone Atelier Armorique. (a) The locations of the three study landscapes of low (A), medium (B), and high (C) agricultural intensity. An example of landscape A shown as (b) a red-greenblue (RGB) image, (c) a discrete land-use map, and (d) a graph of interactions between patches. Note that nodes in (d) are represented by the same color categories as in (c). The three images correspond to the same year (2010).

\section{Results}

3.1. Review of Graph Metrics

3.1.1. Graph Metrics at the Landscape Scale

The bibliographic review resulted in 13 metrics at the whole-landscape scale. For each metric selected, Table 1 shows its calculation, interpretation, ecological meaning, and references. We then discuss the findings according to the reported main attribute (heterogeneity, connectivity, clustering, and assortativity). 
Table 1. Graph metrics selected to describe heterogeneity, connectivity, clustering, and assortativity at the landscape scale.

\begin{tabular}{|c|c|c|c|c|c|}
\hline Group & $\begin{array}{c}\text { Metric } \\
\text { (Abbreviation) }\end{array}$ & Calculation & Interpretation & Ecological Meaning & References \\
\hline $\begin{array}{l}\text { Landscape/graph } \\
\text { heterogeneity }\end{array}$ & $\begin{array}{l}\text { Number of nodes } \\
\text { (N nodes) } \\
\text { Total perimeter } \\
\text { (Total per) }\end{array}$ & $\begin{array}{c}N_{v} \\
\sum_{v \in V(G)}^{N v} \operatorname{per}_{v}\end{array}$ & $\begin{array}{l}\text { How many patches does } \\
\text { the landscape have } \\
\text { Sum of the perimeters of } \\
\text { all patches }\end{array}$ & $\begin{array}{c}\text { The higher the value, } \\
\text { the higher the } \\
\text { heterogeneity of the } \\
\text { landscape }\end{array}$ & [47-49] \\
\hline \multirow{5}{*}{$\begin{array}{l}\text { Landscape/graph } \\
\text { connectivity }\end{array}$} & $\begin{array}{c}\text { Graph density } \\
\text { (Density) } \\
\text { Number of edges } \\
\text { (N edges) }\end{array}$ & $\begin{array}{c}\frac{N_{e}}{\left(N_{v} * \frac{N_{v}}{2}-\frac{N_{v}}{2}\right)} \\
N_{e}=\sum_{\sum_{v}}^{N_{v}} d(v)\end{array}$ & $\begin{array}{l}\text { Ratio of the number of } \\
\text { edges to the number of } \\
\text { possible edges } \\
\text { How many connections } \\
\text { does this landscape have }\end{array}$ & \multirow{3}{*}{$\begin{array}{l}\text { The higher the value, } \\
\text { the greater the connec- } \\
\text { tivity/interactions } \\
\text { between patches }\end{array}$} & \multirow{4}{*}[4,37,50,51,53-55]{} \\
\hline & $\begin{array}{l}\text { Maximum degree } \\
\text { (Max degree) } \\
\text { Mean node degree } \\
\text { (Mean degree) }\end{array}$ & $\begin{array}{c}v \in V(G) \\
\operatorname{Max}_{v \in V(G)} d(v) \\
\sum_{v \in V(G)}^{N_{v}} d(v) \\
\end{array}$ & $\begin{array}{l}\text { Number of links of the } \\
\text { most connected patch } \\
\text { Average number of } \\
\text { connections per patch }\end{array}$ & & \\
\hline & $\begin{array}{l}\text { Median node degree } \\
\text { (Median degree) }\end{array}$ & $\begin{array}{c}N_{v} \\
d(v)_{\text {med }}\end{array}$ & $\begin{array}{l}\text { The "middle" value of the } \\
\text { degree of nodes }\end{array}$ & & \\
\hline & $\begin{array}{l}\text { Graph diameter } \\
\text { (Diameter) }\end{array}$ & $\operatorname{Max}_{u \in V(G)} \in(u)$ & $\begin{array}{l}\text { Longest geodesic distance } \\
\text { (length of the shortest } \\
\text { path) between nodes }\end{array}$ & \multirow{2}{*}{$\begin{array}{l}\text { The lower the value, } \\
\text { the greater the connec- } \\
\text { tivity/interactions } \\
\text { between patches }\end{array}$} & \\
\hline & $\begin{array}{l}\text { Mean node distance } \\
\text { (Mean distance) }\end{array}$ & $\frac{\sum \operatorname{dist}(u, v)}{N^{\circ} \text { paths }} \forall v, u \in V(G)$ & $\begin{array}{l}\text { Average geodesic distance } \\
\text { between patches }\end{array}$ & & {$[53,56,57]$} \\
\hline Cluster metrics & $\begin{array}{l}\text { Number of } \\
\text { communities based } \\
\text { on propagating } \\
\text { labels (N CLP) } \\
\text { Number of } \\
\text { communities based } \\
\text { on greedy } \\
\text { optimization of } \\
\text { modularity } \\
\text { (N CGO) } \\
\text { Number of } \\
\text { communities based } \\
\text { on the leading } \\
\text { eigenvector of the } \\
\text { community matrix } \\
\text { (N CLEV) }\end{array}$ & $\begin{array}{c}\operatorname{Max}[Q] \\
\text { See text (details in [62]) }\end{array}$ & $\begin{array}{l}\text { Number of identified } \\
\text { groups based on different } \\
\text { methods Measures how } \\
\text { clustered the graph is }\end{array}$ & $\begin{array}{c}\text { The higher the value, } \\
\text { the higher the } \\
\text { heterogeneity of the } \\
\text { landscape }\end{array}$ & {$[30,58-62]$} \\
\hline $\begin{array}{l}\text { Assortativity } \\
\text { coefficient }\end{array}$ & $\begin{array}{l}\text { Degree of } \\
\text { assortativity } \\
\text { (Ass deg) }\end{array}$ & $r=\frac{\sum_{x y} x y\left(h_{x y}-a_{x} b_{y}\right)}{\sigma_{a} \sigma_{b}}$ & $\begin{array}{l}\text { The assortativity } \\
\text { coefficient is positive if } \\
\text { similar vertices (based on } \\
\text { some external property) } \\
\text { tend to connect } \\
\text { between them. }\end{array}$ & $\begin{array}{l}\text { The lower the value, } \\
\text { the lower the } \\
\text { robustness of } \\
\text { landscape flow } \\
\text { (of organism) }\end{array}$ & {$[22,30,63,64]$} \\
\hline
\end{tabular}

\section{Heterogeneity}

The number of nodes represents the number of patches in the landscape, while total perimeter is the sum of the perimeters of all patches in the landscape. Both metrics are generally highly correlated. In landscape ecological studies, the landscape area is usually fixed; thus, a higher number of patches or a greater total perimeter result in smaller patches in the landscape. Because some species require particular and/or multiple habitats and resources [42], a higher number of patches (nodes) may benefit specialist species (i.e., habitat specialization; ref. [65] and those requiring multiple resources provided by different habitat types (i.e., through complementation/supplementation; ref. [31], leading to increased levels of species diversity $[47,48]$. An increase in total perimeter and, consequently, a reduction in mean patch size could provide easier access to adjacent patches for many species (i.e., landscape complementation), promote the migration of organisms with shortdistance dispersal such as plants (i.e., cross-habitat spillover; ref. [32], and increase species diversity. In the case of patch size as a productivity indicator for agricultural landscapes, larger patches are often associated with crops; thus, higher productivity is expected in landscapes with both a lower number of nodes and a smaller total perimeter. 


\section{Connectivity}

In an undirected graph (where the distance between $\mathrm{A}$ and $\mathrm{B}$ is equal to the distance between $B$ and $A)$, graph density represents the proportion of current edges $\left(N_{e}\right)$ of all possible edges in the graph $\left(\frac{N_{v}\left(N_{v}-1\right)}{2}\right)$ [52]. This metric is widely used in several areas, such as social network analysis, cybercrime detection, neuroscience, and ecology [12,23,25,66-68]. It ranges from 0 , if edges are not present, to 1 , if all possible edges are present [52]. A denser graph results in more patch interactions (assuming that two adjacent patches will interact), which probably facilitate flux (e.g., insect movements, seed plant dispersal, etc.) between patches. As suggested above, increased patch interactions (as a result of increasing edges in the graph) could result in higher species diversity due to spillover and landscape complementation $[50,51]$.

The number of edges or the degree of a node $v(d(v))$ is the number of edges incident to $v[37,53]$, i.e., the number of neighboring patches of a node (or patch) $v$. Maximum degree is the maximum value of the degrees of nodes $V(G)$, i.e., the patch with more neighbors. Mean node degree is the average value of the degrees of nodes $V(G)$, and median node degree is the middle value of the degrees of nodes $V(G)$ in an ordered list of nodes. A patch with a higher node degree interacts with more patches, resulting in increased species diversity due to edge effects and spillover. Moreover, a higher number of interactions between patches, i.e., mean and median node degree, is an indicator of configurational heterogeneity [4]. Thus, it is expected to increase local diversity (node and edge scale) and decrease landscape diversity $[50,51,54]$. In the same way, the number of edges indicates the number of interactions between patches; it has been used as an indicator of the connectivity in landscapes [55].

Graph diameter is the length of the longest geodesic (i.e., shortest path). If a graph $G$ has several $u-v$ paths, the distance from $u$ to $v(\operatorname{dist}(u, v))$ is the $u-v$ path with the shortest length, while the eccentricity of node $(\in(u))$ is $\operatorname{Max}_{v \in V(G)} \operatorname{dist}(u, v)$ [53]. Thus, we can compute the diameter of a graph by calculating the eccentricity of each node, $\operatorname{Max}_{u \in V(G)} \in(u)$ [53]. It can also be interpreted as the total inter-patch distance an organism would have to traverse to span the two farthest patches [20]. Similarly, mean node distance is the average path length in a graph, obtained by calculating the shortest paths between all pairs of vertices [53]. Both metrics are measures of topological distance between patches. Smaller values of these metrics indicate a more compact and easily traversable landscape $[56,57]$, leading to higher flux and interaction between patches.

\section{Clustering}

In graph theory, a community is a group of nodes densely connected to one another and sparsely connected to other parts of the graph. It can also be defined as a group of nodes similar to one another and dissimilar from the rest of the graph [58-60]. Densely connected nodes may reflect patches closely linked by mutual dispersal events (i.e., bidirectional flux) [30]. Thus, a higher number of (graph) communities in the landscape should lead to greater landscape diversity and benefit to biodiversity. Many community detection techniques have been developed to date and implemented in several areas $[62,69,70]$. In this study, we selected three methods with ecological meaning for community detection: one based on "propagating labels", another based on "greedy optimization of modularity", and the last based on "the leading eigenvector of the community matrix".

To obtain the number of communities on the basis of propagating labels, each node is initialized with a unique label; then, at every iteration of the algorithm, each node adopts the label that a maximum number of its neighbors have, with ties broken uniformly and randomly [58]. We used land-use (LU) categories as labels; thus, as the LU labels propagated through the network, densely connected groups of nodes formed a consensus on their LUs. At the end of the algorithm, nodes with the same LU were grouped together as communities [58]. This algorithm has been used principally in medicine, biogeography, and social networks [24,71-73]. 
An algorithm for community detection based on greedy optimization of modularity was proposed by Clauset et al. [59]. The basis of this algorithm is the concept of modularity $(Q)$. To understand it, consider a particular division of a graph into $k$ communities and a $k \times k$ symmetric matrix $s$ whose element $s_{i j}$ is the fraction of all edges in the graph that links nodes in community $i$ to nodes in community $j$ [61]. The trace of this matrix $\operatorname{Tr} e=\sum_{i} s_{i i}$ gives the fraction of edges in the graph that connect nodes in the same community, while the row or column sums $a_{i}=\sum_{j} s_{i j}$ represent the fraction of edges that connect nodes in community $i$, whose value will be $a_{i} a_{j}$ if there are random connections between vertices [61].

$$
Q=\sum_{i}\left(s_{i i}-a_{i}^{2}\right)
$$

Thus, it measures the fraction of edges in the graph that connect nodes of the same community minus the expected value of the same quantity in a graph with the same community divisions but random connections between nodes [61]. Values typically fall in the range of about 0.3 to 0.7 , with higher values indicating strong community structure, i.e., there are many edges within communities and only a few between them, with 0 indicating random connections between nodes $[59,61]$. The algorithm starts with each vertex being the sole member of a community of one; then, communities whose amalgamation produces the largest increase in $Q$ are repeatedly joined together until there is just one community [59]. This procedure is probably one of the most frequently used, with examples from neuroscience, biogeography, social networks, etc. [72,74,75].

The algorithms that find communities on the basis of the leading eigenvector of the community matrix also maximize modularity, but they explain it with a matrix-based approach [62]. Below, we show the modularity coefficient for optimization in algebraic terms.

$$
Q=\frac{1}{2 N_{e}} \sum_{i j}\left[A_{i j}-P_{i j}\right] \delta\left(g_{i}-g_{j}\right),
$$

where $N_{e}$ is the number of edges in the network, $A_{i j}$ is the current number of edges between a particular pair of nodes $i$ and $j, \delta\left(g_{i}-g_{j}\right)=1$ if group $i$ is the same as $j$ and 0 otherwise [62], and $P_{i j}=\frac{K_{i} K_{j}}{2 N_{e}}$, where $K_{i}$ and $K_{j}$ are the node degrees of $i$ and $j$ in the real graph; thus, the null model follows the same node degree distribution as the real graph [62]. This method has been used in biogeography and social graphs [24,72].

\section{Assortativity}

A network is said to show assortative mixing if nodes of high degree in the network tend to be connected to other nodes of high degree [64]. Thus, a negative value means that patches with many connections tend to connect to others of low degree, i.e., patches that are close to several other patches are not close to each other. This measure provides information about a network's structure and robustness $[30,63]$. Negative values mean that flow relies on a few nodes of high degree, making the landscape less robust [30]. That is, if these nodes disappear, much of the flow (i.e., organisms movement, seed dispersal, etc.) would also disappear, with negative consequences for population dynamics (i.e., no immigration, which leads to extinction) and, thus, decreased species diversity in the landscape. Newman $[22,64]$ proposed a standard Pearson correlation coefficient to quantify the amount of assortative mixing.

$$
r=\frac{\sum_{x y} x y\left(h_{x y}-a_{x} b_{y}\right)}{\sigma_{a} \sigma_{b}},
$$

where $a_{x}$ and $b_{y}$ are the fraction of edges that start and end at vertices with values $x$ and $y$, respectively, $\sigma_{a}$ and $\sigma_{b}$ are the standard deviations of the distributions $a_{x}$ and $b_{y}$, and $h_{x y}$ is the fraction of all edges in the network that join together vertices with values $x$ and $y$ for the scalar variable of interest, i.e., node degree. This metric is in the range $[-1 \leq r \leq 1]$, with 
zero for no assortative mixing, positive values for assortative mixing, and negative values for disassortative mixing. It has been widely used to analyze many biological, neural, physics, and social graphs [21,22,30,76,77].

\subsubsection{Graph Metrics at the Local Scale}

We propose 10 graph metrics at the local scale, classified into three groups according to their main attributes (node importance, compositional heterogeneity, or configurational heterogeneity; Table 2). Similar to the previous section, for each metric, its calculation, interpretation, and ecological meaning are given, and references are cited.

Table 2. Graph metrics describing landscape at the local scale, considering node importance and compositional and configurational heterogeneity.

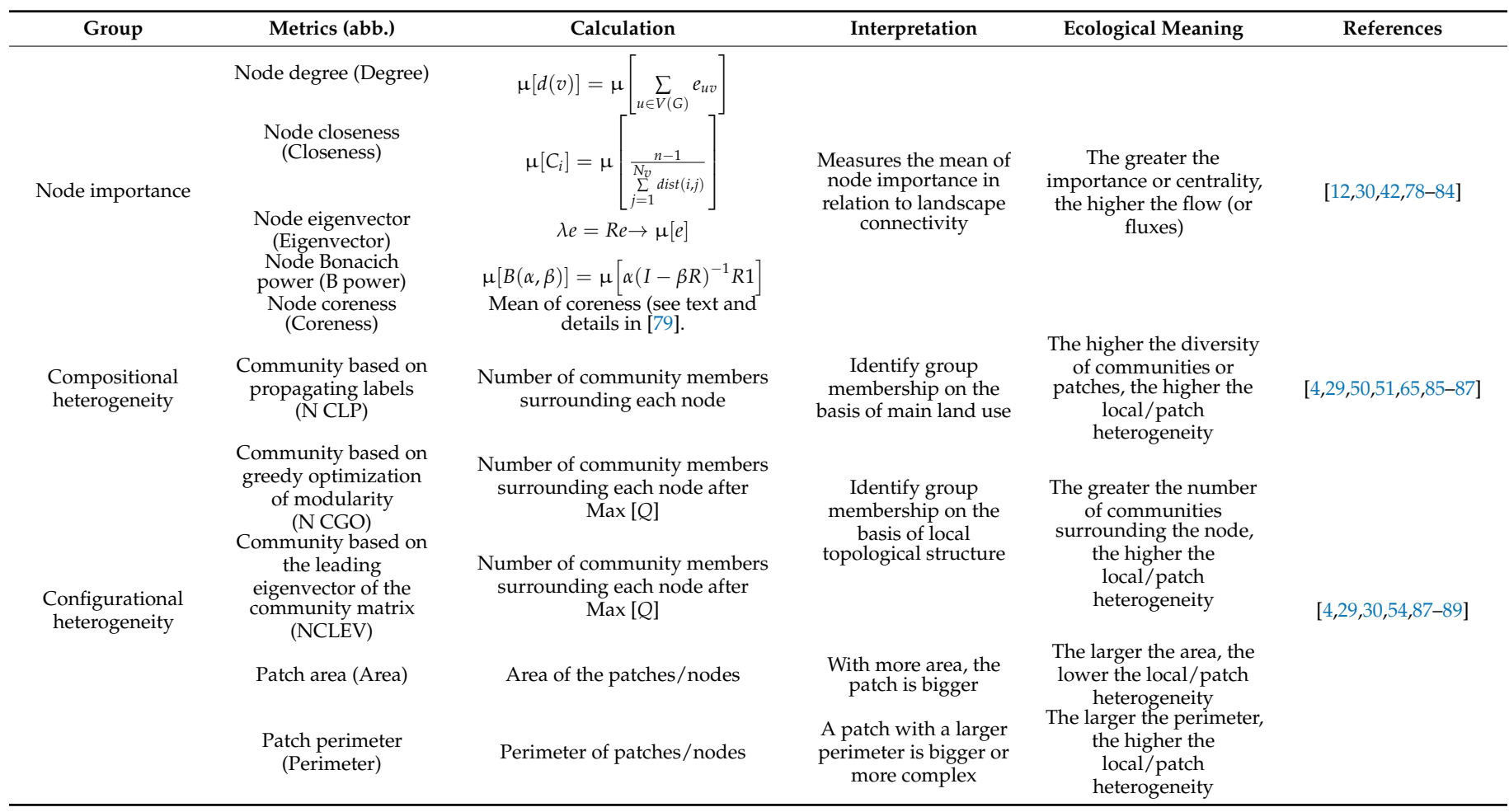

Node Importance/Centrality

Borgatti [81] provided a useful classification of flow processes according to the progress of the flow and the mechanism of node-to-node transmission. Depending on the organisms studied, their dispersal abilities, and movements from patch to patch, different measures can be selected to characterize their flow (or movements) in the landscape. We used the degree, closeness, eigenvector Bonacich power, and coreness measures to illustrate the use of metrics for this group. Before presenting them, we first provide a short summary of Borgatti's work [81].

Node-to-node transmission has three types of mechanism: parallel duplication, serial duplication, and transfer. In transfer, everything that flows exists only once in the landscape, whereas, in duplication, everything that flows exists at the node of origin and in all the nodes through which it flows. The difference between parallel and serial duplication is that, in the former, the flow travels to several nodes at the same time, while, in the latter, it moves from node to node.

There are four types of flow propagation: geodesics, paths, trails, and walks. A path is a simple subgraph of a graph whose nodes can be ordered so that two nodes are adjacent if and only if they are consecutive in the list; furthermore, edges and nodes cannot be repeated [53,81]. A geodesic is the shortest path from $u$ to $v$. Trails are a sequence of edges 
in which no edge is repeated, and walks have no restriction in their sequences [53,81]. All paths are trails and all trails are walks, but not every walk is a trail and not every trail is a path (Table 3; ref. [81]).

Table 3. Typology of flow processes and major centrality measures (adapted from [81]). Metrics combining a particular flow propagation trajectory and node-to-node transmission are shown. As an example, a process that shows the particular combination of flow characteristics is given within parentheses.

\begin{tabular}{|c|c|c|c|}
\hline Typology & Parallel Duplication & Serial Duplication & Transfer \\
\hline Geodesics & $d \mathrm{PC} f l u x+d \mathrm{PC}$ connector & $\begin{array}{l}\text { Freeman closeness } \\
\text { (Mitotic reproduction) }\end{array}$ & $\begin{array}{l}\text { Freeman closeness } \\
\text { Freeman betweenness } \\
\text { (Package delivery) }\end{array}$ \\
\hline Paths & $\begin{array}{l}\text { Freeman closeness } \\
\text { Degree centrality } \\
\text { (Internet name server) } \\
\text { Freeman closeness }\end{array}$ & (Viral infection) & (Mooch) \\
\hline Trails & $\begin{array}{l}\text { Degree centrality } \\
\text { (E-mail broadcast) }\end{array}$ & (Gossip) & (Used goods) \\
\hline Walks & $\begin{array}{l}\text { Freeman closeness } \\
\text { Degree centrality } \\
\text { Bonacich eigenvector } \\
\text { (Attitude influencing) }\end{array}$ & (Emotional support) & (Money exchange) \\
\hline
\end{tabular}

Plants and animals show different dispersal or movement strategies that can be critical to their survival in agricultural landscapes [84,90]. Hence, it is necessary to account for all these different mechanisms of dispersal or movement when selecting centrality measures, i.e., metrics using parallel duplication for their diffusion and the different trajectories that follow.

For every metric of this group, a higher value means that the patch has an important role in the landscape flow because it has several connections to other patches (node degree), its neighbors have several connections (eigenvector, Bonacich power, and coreness), or it is close to other patches (closeness). These important or central patches are probably more diverse because more individuals from different species may flow through them [91]. The vegetation productivity of these central patches may also be higher because the flow could increase the arrival of beneficial insects, but it could also be lower due to higher incidence of diseases [91].

The degree of a node can also be defined as the number of paths of length one that emanates from a node; thus, this metric can be regarded as a measure of immediate effects [30,81]. The probability of a patch being part of a flux of organisms (e.g., plants or insects) from neighboring patches may be related to the number of patches surrounding it [12]. This metric, also called "degree centrality", is probably the simplest centrality measure. Its value ranges from 0 , when a node is not connected to other nodes, to $N_{v}-1$, when a node is connected to all other nodes. It has been widely used in the social sciences, as well as in citation counts to assess the impact of scientific research, in neuroscience, in ecological networks, and in the analysis of commercial economic exchange [12,55,83,92-95].

Closeness is based on the degree to which a node is close to all other nodes in the graph or the degree of independence from other nodes to pass everything that flows [82]. It may be understood as the inverse of the average distance between $i$ and all other nodes, and it provides expected values of arrival times of something flowing through the network or the degree of independence from other nodes to pass everything that flows through them $[81,82]$. A node's closeness centrality is calculated as the sum of the geodesic from/to 
all other nodes [81,82]. Beauchamp [96] recommended calculating the relative centrality of a node $i$ as

$$
C_{i}=\frac{n-1}{\sum_{j=1}^{N_{v}} \operatorname{dist}(i, j)} .
$$

Closeness is 1 when $i$ is maximally close to all other nodes and decreases as the average distance between $i$ and the other nodes grows [82]. Values are scaled by multiplying raw closeness by $\left(N_{V}\right)-1$; thus, values range between 0 and 1 .

Borgatti [81] showed that the interpretation of closeness is accurate for two kinds of processes: those in which things flow along the shortest paths and those in which things flow by parallel duplication, regardless of how diffusion occurs, which is the case for seeds. A patch with high closeness may be regarded as well placed in the graph to facilitate the dispersal of plant species across the landscape [30]. This metric has also been used to analyze commercial economic exchange, identify stakeholders to facilitate diffusion-related conservation objectives in landscape ecology, and analyze the organization of transnationals $[55,93,95,97]$.

A node's centrality, based on the eigenvector centrality method, is calculated as the summed connections to other nodes weighted by their centralities, and it corresponds to the values of the first eigenvector of the graph adjacency matrix $R[80,98]$. The centrality of a node is given by the following expression:

$$
\lambda e=R e,
$$

where $R$ is the matrix of adjacencies, $e$ is an eigenvector of $R$ (the centrality value), and $\lambda$ is its associated eigenvalue. Each eigenvector is a factor of $R$, and the associated eigenvalue measures the accuracy with which it can reproduce $R$. Consequently, the largest eigenvalue is preferred $[80,98]$. Its range is between 0 and 1 , with the most important node with a value of 1 . This measure counts walks, which assume that trajectories can not only be circuitous but also revisit nodes and edges multiple times along the way, and that organisms (e.g., seeds) can take multiple "paths" simultaneously [81]. Moreover, it counts the number of walks of all lengths, weighted inversely by length, which emanate from a node. It has been applied to identify stakeholders to facilitate diffusion-related conservation objectives, analyze the organization of transnationals, and identify best patches for the purpose of conservation in landscape ecology $[30,93,97]$. This centrality metric is scaled so that the node with the highest value is 1 .

Bonacich power is very similar to eigenvector centrality but allows greater flexibility. In this metric, it is possible to choose a parameter $\beta$ to vary the degree and direction (positive or negative) of the dependence of each node's score or power on the scores of the other nodes [80]. It is calculated in matrix notation as

$$
B(\alpha, \beta)=\alpha(I-\beta R)^{-1} R 1,
$$

where "I1" is a column vector of ones, $I$ is an identity matrix, and $\alpha$ affects only the length of the vector $B(\alpha, \beta)$. The parameter $\alpha$ is selected so that the sum of squared scores $B(\alpha, \beta)$ is equal to the number of nodes in the network [80]. Centrality values are rescaled to sum to 1 .

On the other hand, whenever the centrality or power of a patch is increased positively by connections to other high-status patches, a positive value is adequate for $\beta$; however, when it is advantageous to be connected to patches with lower scores, a negative value of $\beta$ is necessary [80]. Furthermore, the magnitude of $\beta$ affects the degree to which distant ties are taken into account; as $\beta$ increases in magnitude, the centralities of the other patches are taken more into account, such that $B_{i}(\alpha, \beta)$ becomes a function of both the indirect and the direct ties connecting the patch to the system [80]. Thus, when $\beta=0, B(\alpha, \beta)$ is perfectly correlated with the degree centrality measure, and when $\beta$ is equal to the reciprocal of the largest eigenvalue of $R$ (RLER), $B(\alpha, \beta)$ is perfectly correlated with the 
eigenvector centrality measure. In our analyses (see graph metrics application below), we selected a value of 0.85 for RLER, because it was less correlated to the other measures and consequently, $B(\alpha, \beta)$ could be interpreted as the eigenvector, but with less influence of the farthest nodes. In contrast, Bonacich power with a negative value of $\beta$ could be used, for example, to detect patches less prone to pest attacks because it would highlight patches connected to various other patches unimportant for network flow.

Coreness, proposed by Seidman [67], is a measure of network cohesion. It is based on minimum degree and produces a sequence of subgraphs of gradually increasing cohesion [67]. A subgraph $H$ of graph $G$ induced by set $W$ is a $k$-core (or a core of order $k$ ) if $\forall v \in W: d(v) \geq k$, and $H$ is a maximum subgraph with this property [79]. The core number of a node $v$ is the highest order of a core that contains this node. The core number of maximum order is also called the main core [79]. The algorithm recursively deletes all nodes and edges incident with them of degree less than $k$, and the remaining graph is the $k$-core.

The $k$-core indices of neighbors' patches may be good indicators of the dispersion occurring in a patch [78]. It has been used to identify the most cohesive patches in a pond network and was related to the presence/absence of the European pond turtle, Emys orbicularis L. [99]. It has also been used to analyze protein-protein interactions [100] and to detect influential spreaders in politics [101]. Here, we counted the number of nodes belonging to different communities surrounding the focal node to calculate related metrics.

\section{Compositional Heterogeneity}

To characterize compositional heterogeneity, we used the number of communities based on propagating labels surrounding a node (which is already explained for cluster metrics at landscape scale). Sirami et al. proposed hypotheses regarding crop heterogeneity, i.e., the compositional and configurational heterogeneity of the crop mosaic itself [87]. To describe the effect of compositional crop heterogeneity on biodiversity, they presented four hypotheses: first, biodiversity increases with increasing crop diversity if different crop types can serve as habitats for different specialist species $[65,102]$; second, biodiversity increases with increasing crop diversity through landscape complementation, i.e., different crop types provide different resources required by single species, or if specialist species spill over from other crop types in the landscape into the sampled fields $[50,51,86]$; third, biodiversity decreases with crop diversity if most species have high minimum total habitat area requirements, i.e., they require large amounts of a single crop type [29]; fourth, biodiversity shows a peaked relationship with crop diversity of the landscape [85]. As each node belongs to a community, we counted different community labels surrounding samples, with the expectation of greater biodiversity in samples surrounded by more different communities. According to Sirami et al. [87], the heterogeneity of cover types should increase biodiversity, at least up to a point, in agricultural landscapes.

\section{Configurational Heterogeneity}

We used other community detection methods and the area and perimeter of patches as indicators of configurational heterogeneity. In the case of community membership based on the leading eigenvector of the community matrix and greedy optimization of modularity methods, we used the number of different communities surrounding samples as an indicator of configurational heterogeneity [88]. Configurational crop heterogeneity may enhance biodiversity through several mechanisms [87]. First, if small fields provide easier access to adjacent crop fields for many species, the reduction in mean field size may benefit biodiversity by landscape complementation and by increasing spillover $[4,54,88]$. Second, a decreased mean field size may limit some species by negative edge effects, and species that require large patches will also decrease $[29,54]$. Therefore, as in compositional heterogeneity, a peaked relationship between configurational heterogeneity and biodiversity is expected. As we stated previously, patches in the same community may indicate mutual dispersal between them as a consequence of the denser connections within 
communities [30]; thus, a higher number of communities surrounding the sample denotes higher heterogeneity.

\subsection{Graph Metric Application \\ 3.2.1. Landscape Scale}

We applied the discussed graph metrics to the three landscapes of the Zone Atelier Armorique. In the landscape heterogeneity group, we found a gradient in the number of patches and in the total perimeter from the south to the north, with landscape A having the highest and landscape $C$ having the lowest number of patches and total perimeter (Table 4; Figure 2). In the case of the metrics of the landscape connectivity group, landscape $\mathrm{C}$ had the densest graph compared with landscapes A and B. In contrast, landscape A had the highest and landscape $C$ the lowest number of edges and maximum degree, with landscape $B$ being intermediate. All landscapes showed similar trends in mean and median node degree, indicating a similar number of connections within them. Lastly, there was a $6 \%$ and $9 \%$ difference between the highest and lowest values of graph diameter and mean node distance, respectively (Table 4). The number of communities varied considerably depending on the method used (Table 4).

Table 4. Application of graph metrics at landscape scale for the three landscapes (A, B, C) in the Zone Atelier Armorique in 2010.

\begin{tabular}{|c|c|c|c|c|}
\hline Group & Metric & Landscape A & Landscape B & Landscape C \\
\hline \multirow{2}{*}{$\begin{array}{l}\text { Landscape/graph } \\
\text { heterogeneity }\end{array}$} & Number of nodes & 553 & 506 & 395 \\
\hline & Total perimeter & $314,451.41$ & $295,448.28$ & $252,918.45$ \\
\hline \multirow{7}{*}{$\begin{array}{l}\text { Landscape/graph } \\
\text { connectivity }\end{array}$} & Graph density & $9.96 \times 10^{-3}$ & $11.30 \times 10^{-3}$ & $14.08 \times 10^{-3}$ \\
\hline & Number of edges & 1520 & 1444 & 1096 \\
\hline & Maximum degree & 31 & 29 & 33 \\
\hline & Mean node degree & 5.49 & 5.71 & 5.55 \\
\hline & Median node degree & 4 & 5 & 5 \\
\hline & Graph diameter & 15 & 16 & 16 \\
\hline & Mean node distance & 6.32 & 6.72 & 6.15 \\
\hline \multirow{3}{*}{ Cluster metrics } & $\begin{array}{l}\text { Number of communities based on } \\
\text { propagating labels }\end{array}$ & 3 & 6 & 5 \\
\hline & $\begin{array}{l}\text { Number of communities based on greedy } \\
\text { optimization of modularity }\end{array}$ & 6 & 7 & 8 \\
\hline & $\begin{array}{l}\text { Number of communities based on the leading } \\
\text { eigenvector of the community matrix }\end{array}$ & 12 & 12 & 11 \\
\hline $\begin{array}{l}\text { Assortativity } \\
\text { coefficient }\end{array}$ & Degree of assortativity & -0.20 & -0.18 & -0.13 \\
\hline
\end{tabular}

Figure 3 shows the number and arrangement of the communities based on greedy optimization of modularity. Modularity ranged from 0.711 to 0.725 , with a mean of 0.719 , indicating strong community structure of the three landscapes studied. Landscape $C$ had the highest and landscape A the lowest number of communities (Figure 3). We obtained values between 0.720 and 0.755 , with a mean of 0.733 , for communities on the basis of the leading eigenvector of the community matrix, indicating even more community structure than shown by the greedy optimization method. However, the differences between landscapes were lower. The propagating labels method for the number of communities showed the greatest differences between landscapes, with landscape $B$ having the highest number of communities and landscape A the lowest (Table 4). 

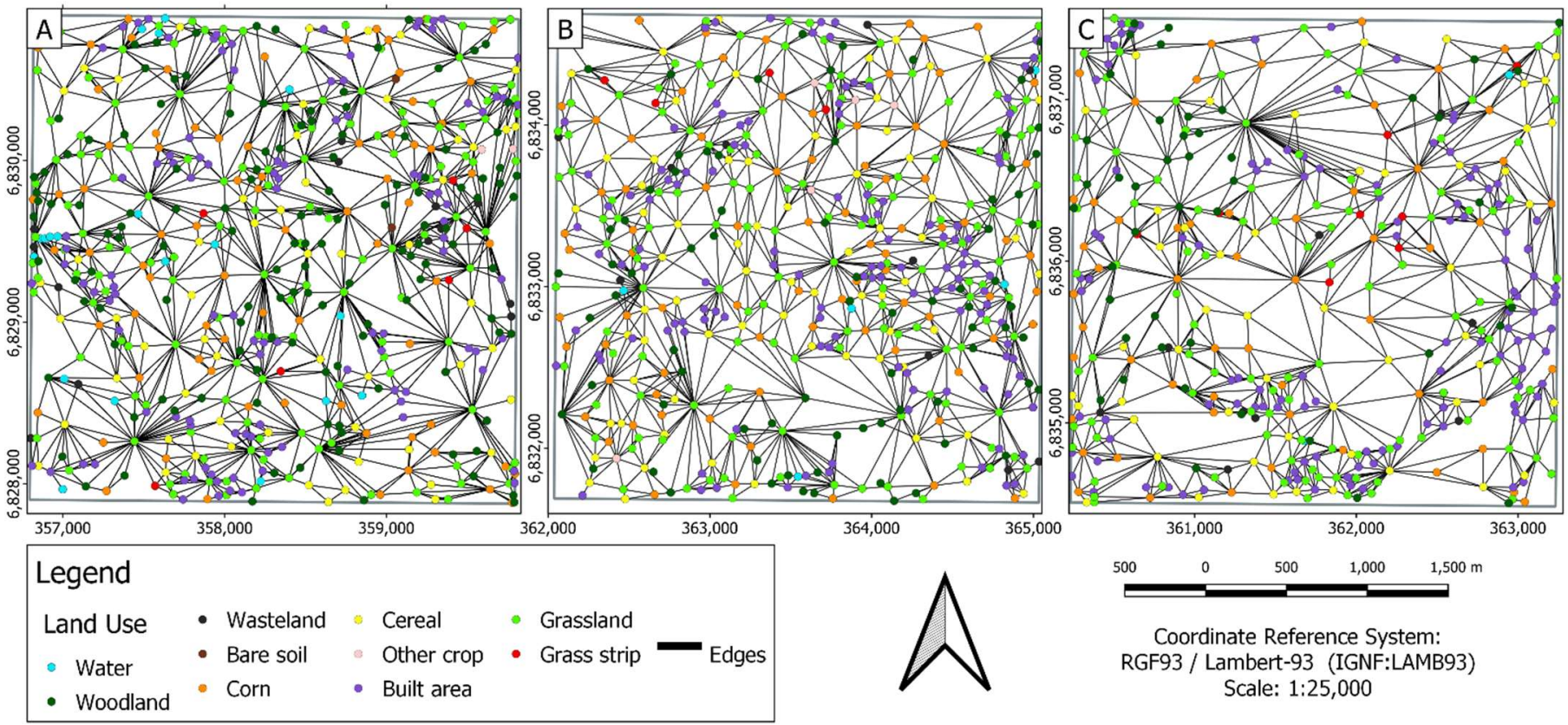

Figure 2. Graphs representing the landscapes $(\mathbf{A}-\mathbf{C})$ in the Zone Atelier Armorique. Different node colors represent different land uses in the patches. Several differences are evident in the characteristics of each graph: the number of nodes and edges are the most notable.

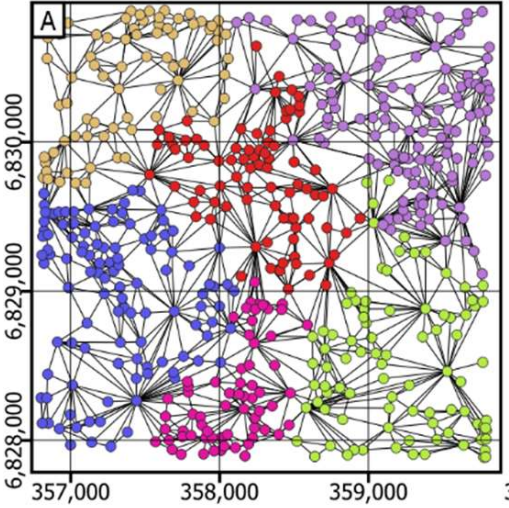

\begin{tabular}{|c|c|c|c|c|c|c|c|c|}
\hline \multicolumn{9}{|l|}{ Legend } \\
\hline Node membership & $\bullet$ & 2 & $\bullet$ & 4 & - & 6 & - 8 & Edges \\
\hline - 1 & $\circ$ & 3 & $\bullet$ & 5 & $\circ$ & 7 & & - \\
\hline
\end{tabular}
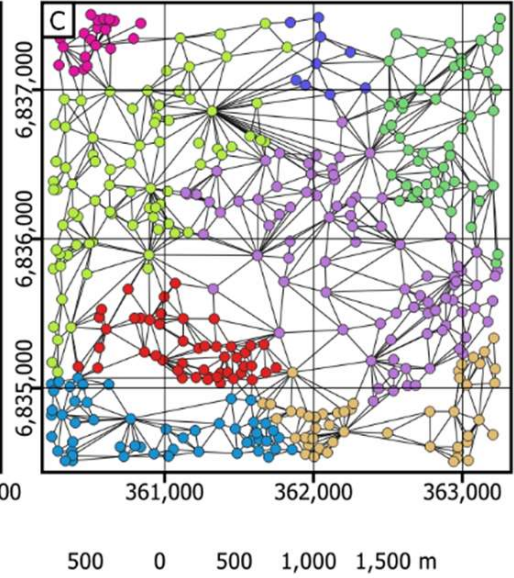

Coordinate Reference System: RGF93 / Lambert-93 (IGNF:LAMB93)

Figure 3. Graphs representing communities in landscapes (A-C) in the Zone Atelier Armorique. Each color represents a different community (from 1 to 8 ) based on greedy optimization of modularity.

Lastly, the degree of assortativity was higher in landscape C, indicating that it was more robust than landscape A when considering the flow of an organism, for example, either a pest or beneficial insect. However, the three landscapes had negative values, indicating that flow relied on a few nodes with high degree (Table 4).

\subsubsection{Local Scale}

At the local scale, the three contrasting nodes in landscape B had very different degrees (Table 5; Figure 4), with node 454 being the least important when landscape connectivity was considered, i.e., there was lower flow through it and more dispersal or movements through node 208. However, depending on the metric (closeness, eigenvector, B power, 
or coreness), both nodes 134 and 208 could be the most central (Table 5). In the case of compositional heterogeneity, node 208, being the most compositionally diverse, had edges to three different communities. In contrast, node 134 had more configurational heterogeneity according to the other two community methods (Table 5).

Table 5. Application of graph metrics at the local scale of landscape B in the Zone Atelier Armorique in 2010. The metrics of the three groups are given for three contrasting nodes 134, 208, and 454 .

\begin{tabular}{|c|c|c|c|c|}
\hline Group & Metric & Node 134 & Node 208 & Node 454 \\
\hline \multirow{5}{*}{ Node importance } & Node degree (degree) & 14 & 29 & 2 \\
\hline & Node closeness (closeness) & 0.20 & 0.18 & 0.16 \\
\hline & Node eigenvector (eigenvector) & 0.05 & 1 & 0.06 \\
\hline & Node Bonacich power (B Power) & $4.96 \times 10^{-3}$ & $12.13 \times 10^{-3}$ & $1.51 \times 10^{-3}$ \\
\hline & Node coreness (Coreness) & 4 & 4 & 2 \\
\hline $\begin{array}{l}\text { Compositional } \\
\text { heterogeneity }\end{array}$ & $\begin{array}{c}\text { Community based on propagating } \\
\text { labels (N CLP) }\end{array}$ & 2 & 3 & 1 \\
\hline \multirow{4}{*}{$\begin{array}{l}\text { Configurational } \\
\text { heterogeneity }\end{array}$} & $\begin{array}{l}\text { Community based on greedy } \\
\text { optimization of modularity (N CGO) }\end{array}$ & 5 & 2 & 1 \\
\hline & $\begin{array}{l}\text { Community based on the leading } \\
\text { eigenvector of the community } \\
\text { matrix (NCLEV) }\end{array}$ & 3 & 2 & 1 \\
\hline & Patch area $\left(\mathrm{m}^{2}\right)$ & $82,877.01$ & $197,840.49$ & 903.87 \\
\hline & Patch perimeter $(\mathrm{m})$ & 1624.94 & 4226.61 & 132.5 \\
\hline
\end{tabular}
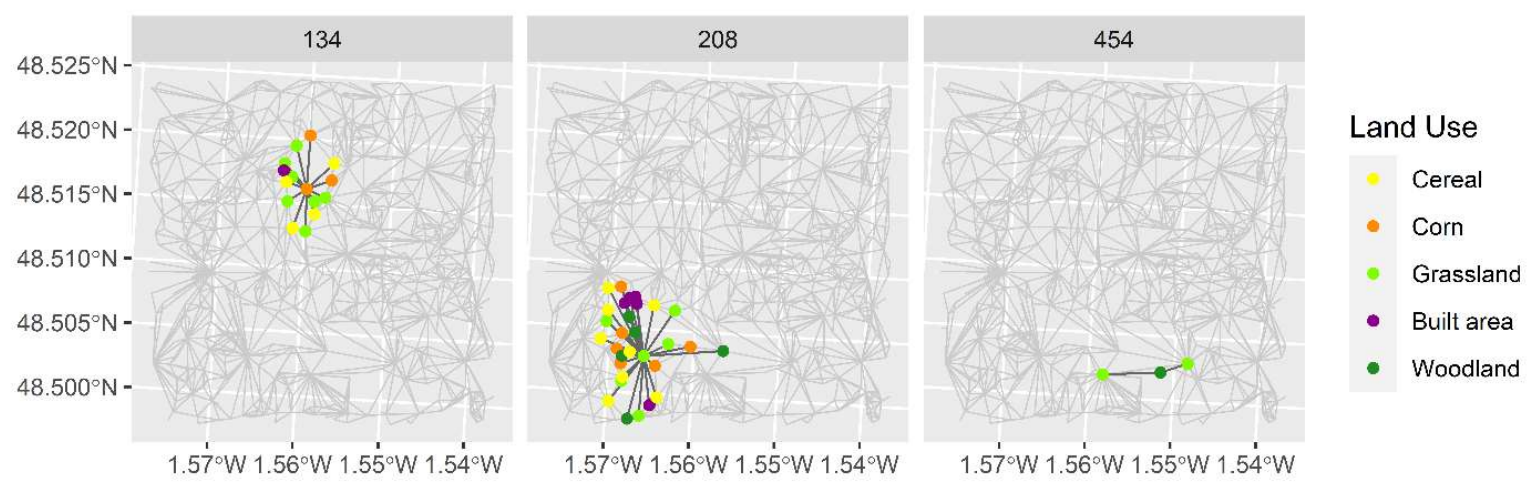

Figure 4. Graphs representing three contrasting nodes selected from landscape B in 2010. Different node colors represent different land uses in the patches. Differences are evident in the degree of each node, i.e., the number of paths of length one that emanate from the node.

\section{Discussion}

This review provided a new general framework for characterizing landscapes, at different scales, employing graph metrics with ecological meaning. Through an extensive literature review, we bring together the graph metrics that have been used in ecological research, describe the main characteristics related to their calculation and the type of information provided, and discuss their potential applications in different ecological contexts. In addition, our employment of the metrics to analyze three actual contrasting landscapes helps to understand their behavior and to explore their potentiality for future research.

\subsection{Graph Metric Analyses}

Landscape metrics are quantitative indices that describe compositional and configurational aspects of landscapes, the latter being typically described as discrete entities or patches [7]. The release of the FRAGSTATS program [103] in 2012 revolutionized landscape structure analysis and made landscape metrics the most common tool to understand biodiversity, ecological processes, and functions at the landscape scale [7,104]. Today, hundreds of different metrics are used to measure landscape patterns [105]. However, some of them 
present problems such as redundancy and high correlation, limited consideration of spatial patterns, and difficulties in interpretation leading to inappropriate inferences $[7,104,106]$. Although some of these problems are also apparent in graph metrics, graph theory presents great potential for understanding processes and functions at the landscape scale and considering the type of landscape phenomenon (plant dispersal, animal movements, fire propagation, etc.). Calabrese and Fagan highlighted the potential of graph theory due to its low data requirement given the benefits it can deliver [107]. Kupfer showed that, for a selection of landscape metrics, there is a tradeoff between (1) data requirements and ease of calculation of the metrics, (2) their basis in structural versus functional properties, and (3) their ease of interpretation [7]. In this sense, graph metrics are at the midpoint between structure and function, but they are usually more difficult to calculate and interpret than the commonly used structural metrics [7].

As demonstrated in our review, graph metrics must be used according to the type of information provided by the metric. While there are some metrics that can be applied at the landscape scale and provide a single value for the whole landscape, others are informative about the role of one node in relation to its neighbors or the rest of the landscape. Among the metrics used to characterize the whole landscape, those that appraise the heterogeneity, connectivity, atomization, or assortativity of the landscape can be differentiated. On the other hand, among the metrics used to characterize the landscape at the local scale, it is possible to distinguish between metrics that are informative about node importance and those that explain its local heterogeneity (compositional and configurational).

Graph/landscape heterogeneity metrics provide information similar to that offered by classic compositional metrics, such as the number of patches and total edge. They can easily be incorporated into a characterization and evaluation of a given landscape, consequently facilitating the analysis by providing both points of view (classical and graph theory analyses).

Several metrics available for graph connectivity at the landscape scale provide information about the quantity of interactions between nodes (maximum degree and mean and median node degree). These descriptive metrics can be complemented by observing the complete distribution of the degrees of the landscape nodes.

On the other hand, the number of edges, mean node distance, and graph density provide information about the number of connections and their density or degree of topological aggregation/disaggregation that are not necessarily in a Euclidean plane. Given that the three metrics are correlated with the number of nodes in the landscape, which in turn could hide important patterns, we recommend modifying these metrics so that their values are independent of the number of nodes. In addition, a particular value of these metrics may be obtained either from a rather "uniform" network or from a network consisting of a very cohesive region (with points of high degree) and a very sparse region (with points of low degree; ref. [67]), which could also hide landscape patterns.

Graph diameter, which represents the topological distance between the two farthest nodes, is an easily interpretable metric, which allows consideration of processes associated with connectivity that are not necessarily Euclidean. However, it is necessary to account for its value being influenced by differences in any of the edges that make up the diameter, rendering changes or differences in other parts of the graph invisible.

Cluster metrics are probably the most dissimilar to the classic metrics of landscape ecology. The number of communities based on "greedy optimization of modularity" and "the leading eigenvector of the community matrix" are mainly metrics measuring the configurational heterogeneity of the landscape, while the number of communities based on "propagating labels" is related to both configurational and compositional heterogeneity.

The last metric at the landscape scale, the degree of assortativity, is also very different from any other classic metric of landscape ecology. It allows relating connectivity between nodes to some external property. Here, the number of connections is used to measure their assortativity, but any other characteristics of the nodes can potentially be used. For example, if information is available on patches with a certain disease, it is possible to evaluate the 
degree to which the disease clusters or whether it is dispersed in the landscape, which could provide valuable information for its management.

At the local scale, metrics associated with node importance, which indicates the extent of connectivity of the nodes, are configurational metrics that demonstrate their significance in relation to others, revealing local flow capacity. The different methods for measuring them represent the different ways to see their topology. These methods may be related to the compositional metric, edge density (which measures the $\mathrm{m} /$ ha of a class per patch, class of land use/land cover (LULC), or landscape), but the methods themselves do not measure the flow between patches.

Compositional heterogeneity is one of the newest measures, along with cluster metrics, which identifies communities or groups in the landscape on the basis of LULC and the amount of connectivity between nodes. It describes heterogeneity at the local scale as a function of the first-order neighborhood. In the configurational heterogeneity group, patch area and perimeter are metrics that provide the same information as the classic configurational metrics obtained from raster data. This occurs because the configuration of each node of the graph contains the area and perimeter information of each patch as an attribute. This is useful since it is possible to add other patch attributes, such as temperature, primary productivity, and type of management. On the other hand, the other two metrics in this group measure the number of communities surrounding each node. It is not possible to obtain this information by classic metrics of landscape ecology.

\subsection{Implementation of Graph Metrics}

As Kupfer stated, graph metrics are more difficult to calculate and interpret than commonly used structural metrics [7]. This calculation difficulty is in part due to the lack of software that can construct and analyze graphs [7]. However, the development of new packages in open-source software, such as $R$, is providing the opportunity to overcome this barrier by using them in conjunction with other tools, such as sf, raster, and landscape metrics, to analyze landscapes $[104,108-110]$ or specific to graphs such as graph4lg, Makurhini, and igraph [44,111,112]. Unlike other software for calculating graphbased metrics, $R$ allows integration of large workflows and reproducibility of analyses, as it is available for the most common operating systems [108]. Given the many approaches to quantify spatial patterns (e.g., landscape, graph, and surface metrics) and that there is no one-size-fits-all solution [105], different complementary approaches may be required for the same study, and $R$ is the program with the highest potential to offer them.

However, by reducing technological barriers, the same problems that occurred with FRAGSTATS development, i.e., the use and misuse of metrics due to the problems mentioned by Gustafson, Kupfer, and $\mathrm{Li}$ and $\mathrm{Wu}$ are possible $[7,104,106]$. One of these problems is the assumption that the matrix is homogeneous, when, in fact, it may neither be uniformly uninhabitable nor serve as a total barrier to the movement of a certain organism [7]. Many graph metrics are based on this binary perspective of the landscape. For instance, Rayfield et al. identified 63 graph metrics, of which 29 are calculated using simple connections between habitat patches, i.e., topological relationships or the "Euclidean nearest neighborhood" metric [20]. The other 34 metrics are calculated by including node and/or edge weights characterizing some functional factor, such as patch area, the distance between patches, or the cost to move between patches. However, both types of metric (weighted and unweighted) are analyzed from the perspective that habitat patches are nodes and ignore the heterogeneity of the matrix.

In addition, one of the criticisms of the classic metrics obtained from landscapes viewed as mosaics is that many tend to characterize the landscape in a structural rather than a functional way, and they do not necessarily have a relationship with the processes that occur in the landscape $[7,106]$. Although the graphs in this study are based on mosaics, nodes can incorporate qualitative and quantitative information, and the links can incorporate weights, allowing the graphs to better represent the relationships between the structure and function of the landscape [113]. For example, edges between nodes can be weighted on the basis 
of patch similarity in terms of genetics, species richness, agricultural practices, or another relevant ecological factor [105]. Using graphs to analyze the processes and functions of landscapes through their metrics offers an opportunity to go beyond the emphasis on structural properties inherent in most traditional landscape metrics; however, the degree to which this can be accomplished with graphs is determined by the way in which nodes and edges are defined and how metrics are calculated $[7,18,20,114]$. To the extent that information and/or resources are available, mark-recapture studies or species-specific cost surfaces can be used to estimate the movement of organisms between patches. In this way, edges between patches can be more realistically characterized for analysis.

\subsection{Case Study and Final Remarks}

The case study investigated three contrasting landscapes that represent a gradient of low to high hedgerow network density and farming practice intensity from the north to the south (Figure 1), which affects fauna and flora and the ecological processes in different ways $[38,39,115]$. The application of graph metrics showed clear differences between the areas studied when landscape heterogeneity, connectivity, and assortativity were measured from graphs (the number of nodes, total perimeter, graph density, number of edges, and degree of assortativity), confirming the ecological differences already reported in other studies. Otherwise, unclear differences can be observed from graph metrics that consider aggregated values of neighborhood relationships or clustering at the node level, possibly due to the topological configuration of the nodes in the graph (based on the LULC classes and the number of connections present in each community).

At the local scale, when we compared node degree with other graph metrics (from the node importance and compositional and configurational heterogeneity groups), it was not possible to see a clear pattern associated with it. In these metrics, topological relationships are used, but they do not necessarily represent the relationships that occur in a Euclidian context.

Lastly, using graph metrics, we succeeded in highlighting the main differences between the three landscapes, as well as the more subtle differences that can also explain ecological processes/patterns. Thus, graph metrics offer an integrative (and deeper) view of landscapes by considering both structure and function.

\section{Conclusions}

Graph metrics allow the description of landscape heterogeneity in the same way as classical metrics, and they consider compositional, configurational, and topological characteristics. Some graph metrics that consider topology provide new information owing to the application of topological relationships that are not necessarily based on a Euclidian space.

A graph analytical perspective enables the incorporation of new biophysical information related to ecological processes beyond the conventional LULC categories applied in classical landscape analysis. Consequently, more complex ecological questions can be addressed, for example, relationships between ecological processes at the level of topology or topological relationships between processes beyond the traditional dimensions.

The development of new software, functions, and libraries oriented toward calculating graph metrics and the incorporation of new metrics will allow expanded use of a graphbased analytical perspective in the framework of landscape ecology. Further studies are necessary that relate graph metrics with ecological processes at the landscape scale. This is a promising area for future scientific development in the field of landscape ecology.

Author Contributions: Conceptualization, M.D.M., F.d.1.B. and A.A.; literature review: F.d.1.B.; writing-original draft preparation, F.d.l.B., M.D.M. and A.A.; critically revised work, S.R.-P. and A.D.; supervision, M.D.M. All authors have read and agreed to the published version of the manuscript. 
Funding: This research was funded by the Center of Applied Ecology and Sustainability (CAPES) project code PIA/BASAL FB0002. and also received funding from the European Union's H2020 research and innovation program under the Marie Sklodowska-Curie grant agreement No. 691149 (SuFoRun).

Informed Consent Statement: Not applicable.

Data Availability Statement: Not applicable.

Acknowledgments: We thank the LETG-Rennes-COSTEL lab for preparing original land-cover maps.

Conflicts of Interest: The authors declare no conflict of interest.

\section{References}

1. Turner, M.G.; Gardner, R.H. Landscape Ecology in Theory and Practice: Pattern and Process, 2nd ed.; Springer: New York, NY, USA, 2015; ISBN 9781493927944.

2. MacArthur, R.H.; Wilson, E.O. The Theory of Island Biogeography; Princeton University Press: Princeton, NJ, USA, 1967.

3. Wiens, J.A. Landscape mosaics and ecological theory. In Mosaic Landscapes and Ecological Processes; Springer: Dordrecht, The Netherlands, 1995; pp. 1-26.

4. Fahrig, L.; Baudry, J.; Brotons, L.; Burel, F.G.; Crist, T.O.; Fuller, R.J.; Sirami, C.; Siriwardena, G.M.; Martin, J.L. Functional landscape heterogeneity and animal biodiversity in agricultural landscapes. Ecol. Lett. 2011, 14, 101-112. [CrossRef] [PubMed]

5. Pascual-Hortal, L.; Saura, S. Comparison and development of new graph-based landscape connectivity indices: Towards the priorization of habitat patches and corridors for conservation. Landsc. Ecol. 2006, 21, 959-967. [CrossRef]

6. Saura, S.; Pascual-Hortal, L. A new habitat availability index to integrate connectivity in landscape conservation planning: Comparison with existing indices and application to a case study. Landsc. Urban. Plan. 2007, 83, 91-103. [CrossRef]

7. Kupfer, J.A. Landscape ecology and biogeography: Rethinking landscape metrics in a post-FRAGSTATS landscape. Prog. Phys. Geogr. 2012, 36, 400-420. [CrossRef]

8. Forman, R.T.T. Land Mosaics: The Ecology of Landscapes and Regions; University Press: Cambridge, UK, 1995; ISBN 9780521479806.

9. Farina, A. Ecology, Cognition and Landscape. Linking Natural and Social Systems; Décamps, H., Ed.; Springer: Urbino, Italy, 2010; ISBN 978-90-481-3137-2.

10. Estrada, E.; Fox, M.; Higham, D.J.; Oppo, G.-L. Network Science; Springer: London, UK, 2010; ISBN 978-1-84996-396-1.

11. Green, D.G.; Klomp, N.; Rimmington, G.; Sadedin, S. Complexity in Landscape Ecology; Springer: Dordrecht, The Netherlands, 2006; ISBN 978-1-4020-4287-4.

12. Ager, A.A.; Day, M.A.; Finney, M.A.; Vance-Borland, K.; Vaillant, N.M. Analyzing the transmission of wildfire exposure on a fire-prone landscape in Oregon, USA. For. Ecol. Manag. 2014, 334, 377-390. [CrossRef]

13. Aquilué, N.; Filotas, É.; Craven, D.; Fortin, M.; Brotons, L.; Messier, C. Evaluating forest resilience to global threats using functional response traits and network properties. Ecol. Appl. 2020, 30. [CrossRef]

14. Green, D.G. Connectivity and complexity in ecological systems. Pacific Conserv. Biol. 1994, 1, 194-200. [CrossRef]

15. Hanski, I.; Alho, J.; Moilanen, A. Estimating the parameters of survival and migration of individuals in metapopulations. Ecology 2000, 81, 239-251. [CrossRef]

16. Uuemaa, E.; Antrop, M.; Roosaare, J.; Marja, R. Landscape Metrics and Indices: An Overview of Their Use in Landscape Research Living Reviews in Landscape Research. Living Rev. Landsc. Res. 2009, 3, 1-28. [CrossRef]

17. Cantwel, M.; Forman, R. Landscape graphs: Ecological modeling with graph theory to detect configurations common to diverse landscapes. Landsc. Ecol. 1993, 8, 239-255. [CrossRef]

18. Foltête, J.C.; Savary, P.; Clauzel, C.; Bourgeois, M.; Girardet, X.; Saharoui, Y.; Vuidel, G.; Garnier, S. Coupling landscape graph modeling and biological data: A review. Landsc. Ecol. 2020, 35, 1035-1052. [CrossRef]

19. Godet, C.; Clauzel, C. Comparison of landscape graph modelling methods for analysing pond network connectivity. Landsc. Ecol. 2020, 9, 735-748. [CrossRef]

20. Rayfield, B.; Fortin, M.-J.; Fall, A. Connectivity for conservation: A framework to classify network measures. Ecology 2011, 92, 847-858. [CrossRef] [PubMed]

21. De Franciscis, S.; Johnson, S.; Torres, J.J. Enhancing neural-network performance via assortativity. Phys. Rev. E Stat. Nonlinear Soft Matter Phys. 2011, 83, 36114. [CrossRef]

22. Newman, M.E.J. Mixing patterns in networks. Phys. Rev. E Stat. Phys. Plasmas Fluids Relat. Interdiscip. Top. 2003, 67, 13. [CrossRef]

23. Khosla, N.; Marsteller, J.A.; Hsu, Y.J.; Elliott, D.L. Analysing collaboration among HIV agencies through combining network theory and relational coordination. Soc. Sci. Med. 2016, 150, 85-94. [CrossRef]

24. Wong, F.M.F.; Tan, C.W.; Sen, S.; Chiang, M. Quantifying political leaning from tweets, retweets, and retweeters. IEEE Trans. Knowl. Data Eng. 2016, 28, 2158-2172. [CrossRef]

25. Han, C.; Kono, K.; Tanaka, S.; Kawakita, M.; Takeuchi, J. Botnet detection using graphical lasso with graph density. In Lecture Notes in Computer Science; Springer: Berlin/Heidelberg, Germany, 2016; Volume 9947, pp. 537-545.

26. Urban, D.; Keitt, T. Landscape connectivity: A graph-theoretic perspective. Ecology 2001, 82, 1205-1218. [CrossRef]

27. Dale, M.; Fortin, M.-J. Spatial Analysis a Guide for Ecologists, 2nd ed.; Cambridge University Press: Cambridge, UK, 2014; ISBN 978-0-52114350-9. 
28. Laita, A.; Kotiaho, J.S.; Mönkkönen, M. Graph-theoretic connectivity measures: What do they tell us about connectivity? Landsc. Ecol. 2011, 26, 951-967. [CrossRef]

29. Mony, C.; Abadie, J.; Gil-Tena, A.; Burel, F.; Ernoult, A. Effects of connectivity on animal-dispersed forest plant communities in agriculture-dominated landscapes. J. Veg. Sci. 2018, 29, 167-178. [CrossRef]

30. Upadhyay, S.; Roy, A.; Ramprakash, M.; Idiculla, J.; Kumar, A.S.; Bhattacharya, S. A network theoretic study of ecological connectivity in Western Himalayas. Ecol. Model. 2017, 359, 246-257. [CrossRef]

31. Dunning, J.B.; Danielson, B.J.; Pulliam, H.R. Ecological Processes That Affect Populations in Complex Landscapes. Oikos 1992, 65, 169-175. [CrossRef]

32. Tscharntke, T.; Tylianakis, J.M.; Rand, T.A.; Didham, R.K.; Fahrig, L.; Batáry, P.; Bengtsson, J.; Clough, Y.; Crist, T.O.; Dormann, C.F.; et al. Landscape moderation of biodiversity patterns and processes - eight hypotheses. Biol. Rev. 2012, 87, 661-685. [CrossRef]

33. Correa Ayram, C.A.; Mendoza, M.E.; Etter, A.; Salicrup, D.R.P. Habitat connectivity in biodiversity conservation: A review of recent studies and applications. Prog. Phys. Geogr. 2016, 40, 7-37. [CrossRef]

34. Uroy, L.; Ernoult, A.; Mony, C. Effect of landscape connectivity on plant communities: A review of response patterns. Landsc. Ecol. 2019, 34, 203-225. [CrossRef]

35. Kwok Lun Cheung, A. Spatial and Temporal Topological Analysis of Landscape Structure Using Graph Theory; University of Auckland: Auckland, New Zealand, 2015.

36. Fall, A.; Fortin, M.J.; Manseau, M.; O’Brien, D. Spatial graphs: Principles and applications for habitat connectivity. Ecosystems 2007, 10, 448-461. [CrossRef]

37. Rahman, S. Basic Graph. Theory; Springer: Cham, Switzerland; Dhaka, Bangladesh, 2017; Volume 9, ISBN 978-3-319-49475-3.

38. Le Coeur, D.; Baudry, J.; Burel, F. Field margins plant assemblages: Variation partitioning between local and landscape factors. Landsc. Urban. Plan. 1997, 37, 57-71. [CrossRef]

39. Alignier, A. Two decades of change in a field margin vegetation metacommunity as a result of field margin structure and management practice changes. Agric. Ecosyst. Environ. 2018, 251, 1-10. [CrossRef]

40. ESRI ArcGIS Desktop. 2016. Available online: https://www.safe.com/training/recorded/esri-arcgis-2016/ (accessed on 4 November 2019).

41. Saura, S.; Pascual-Hortal, L. Conefor SENSINODE 2.2 User's Manual. 2007. Available online: http://www.conefor.org/files/ usuarios/CS22manual.pdf (accessed on 23 October 2020).

42. Julve, P. Baseflor. Index Botanique, Écologique et Chorologique de la Flore de France. Available online: http://philippe.julve. pagesperso-orange.fr/catminat.htm (accessed on 4 November 2019).

43. Labadessa, R.; Alignier, A.; Cassano, S.; Forte, L.; Mairota, P. Quantifying edge influence on plant community structure and composition in semi-natural dry grasslands. Appl. Veg. Sci. 2017, 20, 572-581. [CrossRef]

44. Csardi, G.; Nepusz, T. The igraph software package for complex network research. InterJ. Complex Syst. 2006, 1695, 1-9.

45. Qgis Development Team QGIS Geographic Information System (3.4.5); Open Source Geospatial Foundation: Madeira, Portugal, 2019.

46. R Core Team. R: A Language and Environment for Statistical Computint (3.6.1); R Foundation for Statistical Computing: Vienna, Austria, 2020; Available online: https:/ /www.R-project.org/ (accessed on 23 October 2020).

47. Amici, V.; Landi, S.; Frascaroli, F.; Rocchini, D.; Santi, E.; Chiarucci, A. Anthropogenic drivers of plant diversity: Perspective on land use change in a dynamic cultural landscape. Biodivers. Conserv. 2015, 24, 3185-3199. [CrossRef]

48. Hammill, E.; Hawkins, C.P.; Greig, H.S.; Kratina, P.; Shurin, J.B.; Atwood, T.B. Landscape heterogeneity strengthens the relationship between $\beta$-diversity and ecosystem function. Ecology 2018, 99, 2467-2475. [CrossRef] [PubMed]

49. Poggio, S.L.; Chaneton, E.J.; Ghersa, C.M. Landscape complexity differentially affects alpha, beta, and gamma diversities of plants occurring in fencerows and crop fields. Biol. Conserv. 2010, 143, 2477-2486. [CrossRef]

50. Mandelik, Y.; Winfree, R.; Neeson, T.; Kremen, C. Complementary habitat use by wild bees in agro-natural landscapes. Ecol. Appl. 2012, 22, 1535-1546. [CrossRef] [PubMed]

51. Schneider, G.; Krauss, J.; Boetzl, F.A.; Fritze, M.A.; Steffan-Dewenter, I. Spillover from adjacent crop and forest habitats shapes carabid beetle assemblages in fragmented semi-natural grasslands. Oecologia 2016, 182, 1141-1150. [CrossRef]

52. Wasserman, S. Social Network Analysis: Methods and Applications; Structural Analysis in the Social Sciences; 8; Cambridge University Press: Cambridge, UK, 1994; ISBN 0521387078.

53. West, D.B. Introduction to Graph Theory, 2nd ed.; Prentice Hall: Hoboken, NJ, USA, 2001; ISBN 0-13-014400-2.

54. Concepción, E.D.; Fernandez-González, F.; Díaz, M. Plant diversity partitioning in Mediterranean croplands: Effects of farming intensity, field edge, and landscape context. Ecol. Appl. 2012, 22,972-981. [CrossRef]

55. Herrera-Arroyo, M.L.; Sork, V.L.; González-Rodríguez, A.; Rocha-Ramírez, V.; Vega, E.; Oyama, K. Seed-mediated connectivity among fragmented populations of Quercus castanea (Fagaceae) in a Mexican landscape. Am. J. Bot. 2013, 100, 1663-1671. [CrossRef]

56. Ferrari, J.R.; Lookingbill, T.R.; Neel, M.C. Two measures of landscape-graph connectivity: Assessment across gradients in area and configuration. Landsc. Ecol. 2007, 22, 1315-1323. [CrossRef]

57. Verheijen, B.H.F.; Varner, D.M.; Haukos, D.A. Effects of large-scale wetland loss on network connectivity of the Rainwater Basin, Nebraska. Landsc. Ecol. 2018, 33, 1939-1951. [CrossRef]

58. Raghavan, U.N.; Albert, R.; Kumara, S. Near linear time algorithm to detect community structures in large-scale networks. Phys. Rev. E Stat. Nonlinear Soft Matter Phys. 2007, 76, 036106. [CrossRef] 
59. Clauset, A.; Newman, M.E.J.; Moore, C. Finding community structure in very large networks. Phys. Rev. E Stat. Phys. Plasmas Fluids Relat. Interdiscip. Top. 2004, 70, 066111. [CrossRef] [PubMed]

60. Radicchi, F.; Castellano, C.; Cecconi, F.; Loreto, V.; Paris, D. Defining and identifying communities in networks. Proc. Natl. Acad. Sci. USA 2004, 101, 2658-2663. [CrossRef] [PubMed]

61. Newman, M.E.J.; Girvan, M. Finding and evaluating community structure in networks. Phys. Rev. E Stat. Nonlinear Soft Matter Phys. 2004, 69, 026113. [CrossRef] [PubMed]

62. Newman, M.E.J. Finding community structure in networks using the eigenvectors of matrices. Phys. Rev. E Stat. Nonlinear Soft Matter Phys. 2006, 74, 1-19. [CrossRef] [PubMed]

63. Noldus, R.; Mieghem, P. Van Assortativity in complex networks. J. Complex. Netw. 2015, 3, 507-542. [CrossRef]

64. Newman, M.E.J. Assortative Mixing in Networks. Phys. Rev. Lett. 2002, 89. [CrossRef] [PubMed]

65. Weibull, A.C.; Östman, Ö.; Agranqvist, A. Species richness in agroecosystems: The effect of landscape, habitat and farm management. Biodivers. Conserv. 2003, 12, 1335-1355. [CrossRef]

66. Otterstatter, M.C.; Thomson, J.D. Contact networks and transmission of an intestinal pathogen in bumble bee (Bombus impatiens) colonies. Oecologia 2007, 154, 411-421. [CrossRef]

67. Seidman, S.B. Network structure and minimum degree. Soc. Netw. 1983, 5, 269-287. [CrossRef]

68. Van Wijk, B.C.M.; Stam, C.J.; Daffertshofer, A. Comparing Brain Networks of Different Size and Connectivity Density Using Graph Theory. PLoS ONE 2010, 5, 13701. [CrossRef]

69. Danon, L.; Díaz-Guilera, A.; Duch, J.; Arenas, A. Comparing community structure identification. J. Stat. Mech. Theory Exp. 2005, P09008. [CrossRef]

70. Newman, M.E.J. Communities, modules and large-scale structure in networks. Nat. Phys. 2012, 8, 25-31. [CrossRef]

71. Han, M.; Yan, M.; Cai, Z.; Li, Y.; Cai, X.; Yu, J. Influence maximization by probing partial communities in dynamic online social networks. Trans. Emerg. Telecommun. Technol. 2017, 28. [CrossRef]

72. Rojas, A.; Patarroyo, P.; Mao, L.; Bengtson, P.; Kowalewski, M. Global biogeography of Albian ammonoids: A network-based approach. Geology 2017, 45, 659-662. [CrossRef]

73. Wu, J.; Cao, G.; Sun, X.; Lee, J.; Rubin, D.L.; Napel, S.; Kurian, A.W.; Daniel, B.L.; Li, R. Intratumoral spatial heterogeneity at perfusion MR imaging predicts recurrence-free survival in locally advanced breast cancer treated with neoadjuvant chemotherapy. Radiology 2018, 288, 26-35. [CrossRef]

74. Buglass, S.L.; Binder, J.F.; Betts, L.R.; Underwood, J.D.M. When "friends" collide: Social heterogeneity and user vulnerability on social network sites. Comput. Hum. Behav. 2016, 54, 62-72. [CrossRef]

75. Preti, M.G.; Bolton, T.A.; Van De Ville, D. The dynamic functional connectome: State-of-the-art and perspectives. Neuroimage 2017, 160, 41-54. [CrossRef]

76. Eguíluz, V.M.; Chialvo, D.R.; Cecchi, G.A.; Baliki, M.; Apkarian, A.V. Scale-free brain functional networks. Phys. Rev. Lett. 2005, 94, 018102. [CrossRef]

77. Long, X.; Fonseca, P.; Aarts, R.M.; Haakma, R.; Foussier, J. Modeling cardiorespiratory interaction during human sleep with complex networks. Appl. Phys. Lett. 2014, 105, 203701. [CrossRef]

78. Bae, J.; Kim, S. Identifying and ranking influential spreaders in complex networks by neighborhood coreness. Physica A 2014, 395, 549-559. [CrossRef]

79. Batagelj, V.; Zaversnik, M. An O(m) Algorithm for Cores Decomposition of Networks. Adv. Data Anal. Classif. 2011, 5, 129-145. [CrossRef]

80. Bonacich, P. Power and Centrality: A Family of Measures. Am. J. Sociol. 2002, 92, 1170-1182. [CrossRef]

81. Borgatti, S.P. Centrality and network flow. Soc. Netw. 2005, 27, 55-71. [CrossRef]

82. Freeman, L. Centrality in Social Networks I: Conceptual Clarification. Soc. Netw. 1979, 1, 215-239. [CrossRef]

83. Newman, M.E.J. Networks an Introduction; Oxford University Press: Oxford, UK, 2010; ISBN 0-19-159417-2.

84. Van Dijk, W.F.A.; Van Ruijven, J.; Berendse, F.; de Snoo, G.R. The effectiveness of ditch banks as dispersal corridor for plants in agricultural landscapes depends on species' dispersal traits. Biol. Conserv. 2014, 171, 91-98. [CrossRef]

85. Allouche, O.; Kalyuzhny, M.; Moreno-Rueda, G.; Pizarro, M.; Kadmon, R. Area-heterogeneity tradeoff and the diversity of ecological communities. Proc. Natl. Acad. Sci. USA 2012, 109, 17495-17500. [CrossRef]

86. Gámez-Virués, S.; Perović, D.J.; Perović, P.; Gossner, M.M.; Börschig, C.; Blüthgen, N.; De Jong, H.; Simons, N.K.; Klein, A.-M.; Krauss, J.; et al. Landscape simplification filters species traits and drives biotic homogenization. Nat. Commun. 2015, 6. [CrossRef]

87. Sirami, C.; Gross, N.; Baillod, A.B.; Bertrand, C.; Carrié, R.; Hass, A.; Henckel, L.; Miguet, P.; Vuillot, C.; Alignier, A.; et al. Increasing crop heterogeneity enhances multitrophic diversity across agricultural regions. Proc. Natl. Acad. Sci. USA 2019, 116, 16442-16447. [CrossRef]

88. Fahrig, L.; Girard, J.; Duro, D.; Pasher, J.; Smith, A.; Javorek, S.; King, D.; Lindsay, K.F.; Mitchell, S.; Tischendorf, L. Farmlands with smaller crop fields have higher within-field biodiversity. Agric. Ecosyst. Environ. 2015, 200, 219-234. [CrossRef]

89. Hass, A.L.; Kormann, U.G.; Tscharntke, T.; Clough, Y.; Baillod, A.B.; Sirami, C.; Fahrig, L.; Martin, J.L.; Baudry, J.; Bertrand, C.; et al. Landscape configurational heterogeneity by small-scale agriculture, not crop diversity, maintains pollinators and plant reproduction in western Europe. Proc. R. Soc. B Biol. Sci. 2018, 285. [CrossRef]

90. Hodgson, J.G.; Grime, J.P.; Hunt, R.; Thompson, K. The Electronic Comparative Plant. Ecology; Springer Science+Business Media: Dordrecht, The Netherlands, 1995; ISBN 978-94-011-7652-1. 
91. Minor, E.S.; Urban, D.L. A Graph-Theory Framework for Evaluating Landscape Connectivity and Conservation Planning. Conserv. Biol. 2008, 22, 297-307. [CrossRef] [PubMed]

92. Hackett, T.D.; Sauve, A.M.C.; Davies, N.; Montoya, D.; Tylianakis, J.M.; Memmott, J. Reshaping our understanding of species' roles in landscape-scale networks. Ecol. Lett. 2019. [CrossRef] [PubMed]

93. Mbaru, E.K.; Barnes, M.L. Key players in conservation diffusion: Using social network analysis to identify critical injection points. Biol. Conserv. 2017, 210, 222-232. [CrossRef]

94. Rubinov, M.; Sporns, O. Complex network measures of brain connectivity: Uses and interpretations. Neuroimage 2010, 52, 1059-1069. [CrossRef] [PubMed]

95. Vilchis, F.L. Análisis estructural de la red económica de exportaciones e importaciones de la Alianza del Pacífico y el Mercado Común del Sur. Estud. Gerenc. 2016, 32, 319-325. [CrossRef]

96. Beauchamp, M.A. an Improved Index of Centrality. Behav. Sci. 1965, 10, 161-163. [CrossRef]

97. Henriksen, L.F.; Seabrooke, L. Transnational organizing: Issue professionals in environmental sustainability networks. Organization 2016, 23, 722-741. [CrossRef]

98. Bonacich, P. Factoring and weighting approaches to status scores and clique identification. J. Math. Sociol. 1972, 2, 113-120. [CrossRef]

99. Pereira, M.; Segurado, P.; Neves, N. Using spatial network structure in landscape management and planning: A case study with pond turtles. Landsc. Urban. Plan. 2011, 100, 67-76. [CrossRef]

100. Ahmed, H.; Howton, T.C.; Sun, Y.; Weinberger, N.; Belkhadir, Y.; Mukhtar, M.S. Network biology discovers pathogen contact points in host protein-protein interactomes. Nat. Commun. 2018, 9, 1-14. [CrossRef]

101. Sun, H.-L.; Ch'ng, E.; See, S. Influential spreaders in the political Twitter sphere of the 2013 Malaysian general election. Ind. Manag. Data Syst. 2019, 119, 54-68. [CrossRef]

102. Andreasen, C.; Streibig, J.C.; Haas, H. Soil properties affecting the distribution of 37 weed species in Danish fields. Weed Res. 1991, 31, 181-187. [CrossRef]

103. McGarigal, K.; Cushman, S.A.; Ene, E. FRAGSTATS v4: Spatial Pattern Analysis Program for Categorical and Continuous Maps. Computer Software Program Produced by the Authors at the University of Massachusetts (No. 4). 2012. Available online: http:/ / www.umass.edu/landeco/research/fragstats/fragstats.html (accessed on 16 November 2020).

104. Gustafson, E.J. How has the state-of-the-art for quantification of landscape pattern advanced in the twenty-first century? Landsc. Ecol. 2019, 34, 2065-2072. [CrossRef]

105. Frazier, A.E.; Kedron, P. Landscape Metrics: Past Progress and Future Directions. Curr. Landsc. Ecol. Reports 2017, 2 , 63-72. [CrossRef]

106. Li, H.; Wu, J. Use and misuse of landscape Índices. Landsc. Ecol. 2004, 19, 389-399. [CrossRef]

107. Calabrese, J.M.; Fagan, W.F. A comparison-shopper's guide to connectivity metrics. Front. Ecol. Environ. 2004, 2, 529-536. [CrossRef]

108. Hesselbarth, M.H.K.; Sciaini, M.; With, K.A.; Wiegand, K.; Nowosad, J. Landscapemetrics: An open-source R tool to calculate landscape metrics. Ecography 2019, 42, 1648-1657. [CrossRef]

109. Hijmans, R.J. Raster: Geographic Data Analysis and Modeling. R Package. 2020. Available online: https://cran.r-project.org/ package $=$ raster $($ accessed on 23 October 2020).

110. Pebesma, E. Simple features for R: Standardized support for spatial vector data. $R$ J. 2018, 10, 439-446. [CrossRef]

111. Godínez-Gómez, O.; Correa-Ayram, C. Makurhini: Analyzing Landscape Connectivity. 2020. Available online: https:// connectscape.github.io/Makurhini/index.html (accessed on 25 June 2021). [CrossRef]

112. Savary, P.; Foltête, J.; Moal, H.; Vuidel, G.; Garnier, S. graph4lg: A package for constructing and analysing graphs for landscape genetics in R. Methods Ecol. Evol. 2020. [CrossRef]

113. Dale, M.; Fortin, M.J. From Graphs to Spatial Graphs. Annu. Rev. Ecol. Evol. Syst. 2010, 41, 21-38. [CrossRef]

114. Savary, P.; Foltête, J.C.; Moal, H.; Vuidel, G.; Garnier, S. Analysing landscape effects on dispersal networks and gene flow with genetic graphs. Mol. Ecol. Resour. 2021, 21, 1167-1185. [CrossRef] [PubMed]

115. Burel, F.; Baudry, J.; Butet, A.; Clergeau, P.; Delettre, Y.; Le Coeur, D.; Dubs, F.; Morvan, N.; Paillat, G.; Petit, S.; et al. Comparative biodiversity along a gradient of agricultural landscapes. Acta Oecologica 1998, 19, 47-60. [CrossRef] 